\title{
Product Image to Build the Core Competitiveness of Enterprises
}

\author{
Yan Shi ${ }^{1, *}$ and Laura Hjaltaso ${ }^{1}$ \\ ${ }^{1}$ Chengdu Vocational \& Technical College of Industry, Chengdu, China \\ Corresponding Email: 510266833@qq.com
}

\begin{abstract}
As a new specialty research field, Product Image is being paid more attention. This article introduced the concept of Product Image and Core-competition, and illustrated how to conduct Core-competition of enterprise from two aspects of the foundation of Product Image and the communication of Product Image.
\end{abstract}

\section{The concept of product image}

Product identity (PI, product image, more translated into product identity) and chivalrous is refers to the product's appearance, including product geometric shape, color, material and man - machine interface, brand logo graphics, in addition to product packaging, display, advertising, logo, construction, marketing, and service and products related to the subject of the external factors [1].In a broad sense, the product image also includes the product of the enterprise concept, spirit, vision, culture and brand concept, passed to the consumer and the credibility of the establishment of the concept of content.

Product image and the overall image of the enterprise is closely linked, you can imagine, the merits of the product image will have a profound impact on the consumer's psychology. It can stimulate or inhibit the purchase desire of consumers, and then influence the establishment of brand image and enterprise image. Visible, product image design is also an effective means to reflect and maintain the brand image.

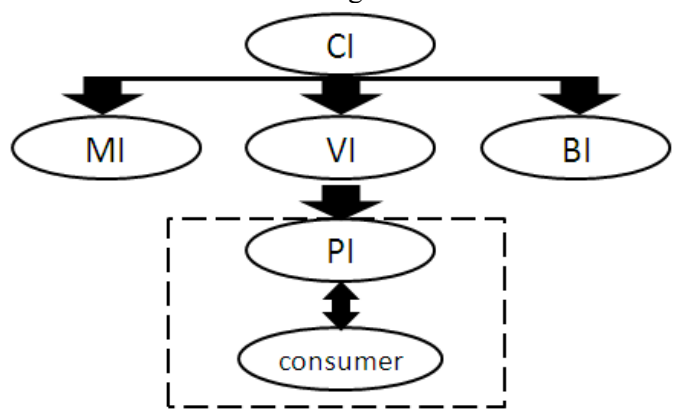

Fig. 1. The relationship of $\mathrm{CI}$ and PI.

As shown in Figure 1, the corporate image includes three parts, respectively is the concept of identification (MI), visual identification (VI), behavior recognition (BI) product image (PI) is a part of the corporate image (CI), but is the most important part, because it is the primary medium for communication between the enterprises and consumers. The recognition of the manufacturing enterprises and enterprises of all business activities are carried out around the product, an enterprise wants to continue to grow and develop, the advent of new products constantly bestselling, let enterprise products by consumers, continue to tap the potential of consumer, consolidate the existing consumer, establish a brand image, let enterprise image rooted in the minds of consumers, and product is the corporate image of the best physical carriers. Therefore, the image of the product naturally becomes the core part of corporate image [2].

\section{The concept of core competence}


Enterprise core competence (Core-Competition) has three basic characteristics: first, it has obvious competitive advantage, the two is to have the potential to expand the application, the three is difficult to imitate competitors. According to the core competence of enterprises, the core competence can be divided into three categories: core products, core technology and core competence. The three are closely related, the product comes from the technology, and the technology comes from the ability. Specific performance for the following aspects:

\subsection{Innovative technology}

Whether the enterprise has the innovation technology often has the decisive function to its development. Technological innovation, it is required to achieve the functionality of the product, uniqueness, as well as beyond the industry's average level of cutting-edge. This advantage of the technology, the enterprise will bring more than ordinary enterprise customer attention and market wide degree.

\subsection{Talents with innovative ability}

Even in the information age, the emergence of a variety of intelligent devices greatly reduced the requirements of human resources, but the ability to innovate is still rare in this era of wealth. Because of innovative technology, and ultimately have to be able to create talent to complete the development and design. Therefore, in an enterprise, innovation talent is always an enterprise can lead the industry trend of the most important factors; it is the necessary condition for the enterprise to build the core competitiveness.

\subsection{Excellent corporate culture}

Compared to the enterprise culture, also belong to the category of abstract consciousness, and some factors of production, the value of corporate culture is often is difficult to be judged, in spite of this, in the modern enterprise system, corporate culture status is is widely recognized and respected. This is because the cultural connotation of a business, the impact of the management of the enterprise, the level of the construction of personnel, such as the more specific aspects. At present, whether a company has excellent culture, is no longer the problem of internal staff attention, more and more consumers in the choice of products, will take into account the culture of a business. This is because a good cultural connotation of the enterprise, it will be in the social responsibility, quality and safety and other aspects of access to consumer trust, which is an important soft power of enterprise construction.

\subsection{Brand influence}

Brand is the product of market competition; more and more enterprises attach importance to brand strategy to create. In today's highly convergence of goods, consumers have been difficult to judge from the value of the level to determine what kind of product is to meet their needs; the use of value has become a lower level of demand. The brand is an important symbol of a company's products, which is different from other enterprise products. It is also a symbol of corporate culture, value and characteristic. In modern society, brand influence means that the degree of accumulation of wealth, with a wide range of influence, good reputation of the brand has a vital role in the development of enterprises. Brand building is a long accumulation of the road, but the destruction of brand is an overnight thing, so to build brand influence and need to enterprise long-term adherence [2].

Product image in a sense is the vision of the core competitiveness of enterprises, product image shaping helps to enhance the core competitiveness of enterprises. For example, Switzerland's Swatch watch, it is through the product image of the re design of a distinctive fashion watch culture, enhance the value and quality of products, and thus enhance the core competitiveness of Swatch company. In this case, the image of the watch product has become the core competitiveness of Swatch company.

\section{The establishment of product image}

Product image design is to design products as the core around people's demand on product, limits for individual participants demand, and changing people's way of life, enhance an image of the quality of life and level of creative activities. Today, people's sense of all kinds of products has been from the internal function and simple geometric shape change design; rise to the inside and outside of the unity of the image of the design. Product of the open, operation, touch, form and other image significance has become the focus of today's product design. For example, the pen holding and writing the image of the induction, the computer keyboard operation image induction, electric iron ironing image induction, etc., are entirely dependent on the external image to display.

The establishment of a good brand image depends on the product of both innovation and a continuation of the image of the design. This can be to understand the product image design: manufacturing enterprises toward the market many kinds of products because of its excellent industrial design innovation system of rigorous planning and gradually advancing, in the minds of the consumer market and establish the unified style and distinctive features of product image. For example, the famous ZIPPO lighter, its product design has long been beyond the shackles of the material function, 
and then evolved into a decorative culture. People buy not only can spark the function, more important is the visual image of products to buy it.

According to AIDA theory, people buy products when the decision-making process is generally divided into four steps: Attention - Interest - Desire - Action. From the above process, we can see that the first step "attention" is particularly important, because it directly led to the production of several steps behind [3]. for the product, in order to get success must be able to attract the attention of the dog dog. Such as automobile rear-view mirror with flashing steering lamp, makes a chic ringing phone. All of these can become to attract the focus of consumer attention; all these attract the attention of consumers and make them interested in place are part of the image of the product. Consumers to buy the product decision-making process, in fact, is the product image from the cognitive to the identity, until the process of purchase, the successful product image design is a decisive factor in the purchase decision of consumers.

\section{Product image transmission}

\subsection{Enterprise publicity}

Enterprise reality and its characteristics are not perceived outside, can not form a corporate image. The formation of the corporate image must be based on the fixed communication channels and means of communication. As mentioned earlier, the spread of corporate image information points for direct communication and indirect communication, direct communication is certainly important, but in terms of the modern enterprise, the mass media to the audience a wide range, information propagation speed quick characteristics become the main channel for the dissemination of corporate image. The mass media can be divided into three forms, the print media, electronic media and outdoor media.

(1) print media

Print media include newspapers, magazines, books, and corporate information and print advertising, etc.. Among them, the newspaper's information dissemination speed is the quickest, the widest range, the greatest impact. The magazine and book information capacity is big, the reading cycle is long, but is affected by the publication cycle, the information dissemination speed is slow. Enterprise printing materials and printing ads targeted at a stronger, faster transmission of information, but the spread of smaller, it is difficult to have a greater impact. Enterprises can choose appropriate printing media according to their own needs [4].

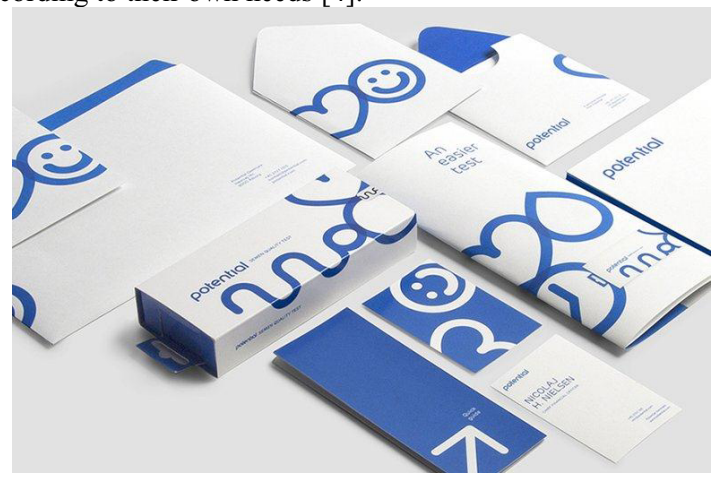

Fig. 2. The enterprise printing media.

(2) electronic media

Electronic media including TV, radio, film, video, DVD and Internet etc.. One of the most important mass media television, radio and the Internet, the rapid development of A new force suddenly rises. TV is the first choice for enterprises to transmit information. Its characteristics are vivid and acoustic painting, spread fast, wide coverage. Broadcast also has the characteristics of fast spread, wide coverage, has been the main form of mass communication, but with the popularity of television, its influence has been shrinking. But the broadcast media has the characteristics of low cost and fast, and it is still an important channel for information dissemination. Internet as the modern information society, the revolutionary mark, along with the rapid growth of the popularity and users of the home computer, the importance of encroaching upon the television broadcasting may also become the main channel for the dissemination of popular electronic [5]. 


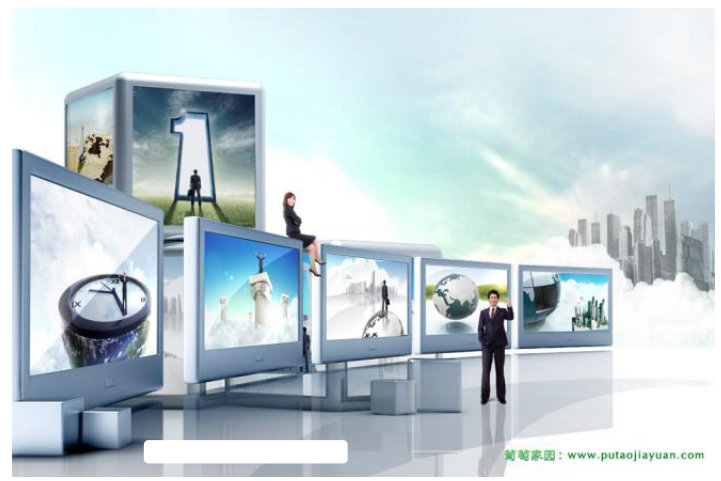

Fig. 3. The enterprise electronic media.

(3) outdoor media

Outdoor media include outdoor public places such as buildings, traffic signs, traffic tools, outdoor electronic screen release advertisement information of various communication media. Outdoor media generally have magnificent and huge volume characteristics; can produce a strong visual impact. Enterprises through outdoor advertising media to promote their own, you can use the characteristics of long duration of outdoor advertising; the information will be repeatedly transmitted to the audience, so that it leaves a deep impression. But the outdoor media coverage is narrow, the information update is slow, so it can only be used as a supplementary means for corporate image communication, and other mass media, the use of organic unity, to complete the task of image communication.

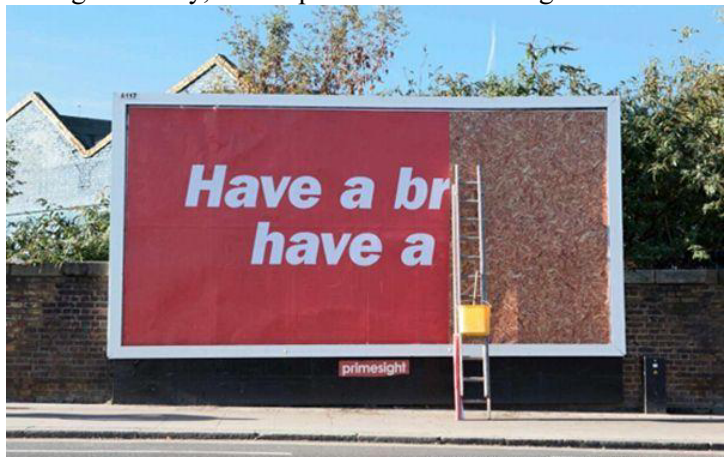

Fig. 4. The enterprise outdoor media.

\subsection{The image of the product itself}

Everything in our daily life products are formed through form, color, material, function of visual image information to people that a specific information, people through the reading of the information to achieve the purpose of understanding and using products. From the perspective of semiotics, the external shape of the product is a series of visual communication symbols, in the production and life has become a specific form of expression of a certain meaning. Product modelling in line with the basic nature of the general symbol, in the structure can be divided into material carrier and emotional carrier. It is based on user's stimulation, stimulate their experience and their past life experiences or behavior associated with a Lenovo, so that consumers have a strong interest in the product, and then form a general impression of the use of the products, this impression had decided whether to continue to buy the same brand of goods, if any products comply with the people's living habits, convenient for people to use and satisfy the function of the product and psychological needs, so that the product will be favored by people, and has been generally recognized, in the course of time, will form a brand, the brand image will be deeply rooted in people's heart, which will not only bring huge the economic benefits to the enterprise, will become a kind of intangible assets, the value of intangible assets is. 


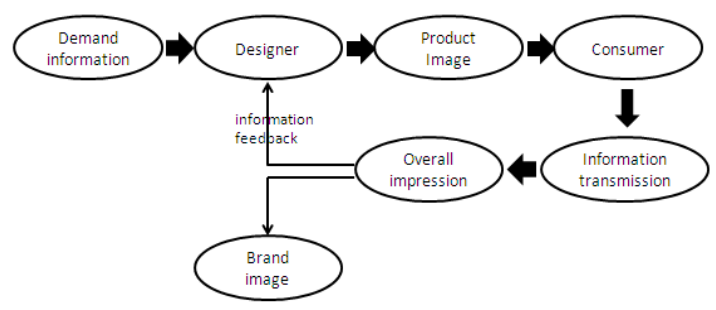

Fig. 5. The sketch map of product image communication.

\section{The non - material development trend of product image}

\subsection{Product image is the formation of the spiritual wealth of the factors}

Coca-Cola has succeeded in transforming a carbonated beverage product into a spirit of culture, promoting the spirit of the United States and the American culture, from tangible to intangible assets. Not only that, we from the world famous enterprises such as Microsoft, IBM, IT, Intel, apple...... Car industry's Mercedes Benz, BMW, Audi, general motors, TOYOTA.....; them every day, every minute of every in the left and right and the control of our way of life and the way of thinking, the impact is already is more than stay in through the use of products to obtain the level of functional requirements, more is a kind of spiritual needs. Cannot be imagined, if one day these companies disappeared overnight, we do not know what life is! Can also constitute our present society?

Product image can be produced by the value of material value, but, more importantly, it can produce the spiritual value of the non - material side. In the process of sustainable development, green design, green economy, and the process of non-material globalization, it is a unique way to stimulate enterprises to consider the concept of image more seriously than before. Globalization forces the domestic market and the domestic economy to move towards global integration at a slow but steady pace. In separated by vast oceans of the global enterprise, globalization has given impetus to the unity of people's experience, wisdom, faith and feelings, these people do not know each other, they come from different countries, speak different languages, believe in different cultures. But these people are gathered together, competing in a land of endless challenges, and they are going to meet these challenges. "Who are we?" the question has never been as urgent as it is now. In fact, they come from the image; they have a business activity, as if they were in charge of their own destiny.

\subsection{The image of the product as a factor of intangible assets}

Product image has become an effective means to establish and maintain the credibility of products. On the one hand, product image as a tangible material function part, with form and function, to meet the basic requirements of people's material; on the other hand, product image as the invisible spirit of part, influence people's attitude towards life and value orientation.

In the foreseeable future, the establishment of product image reputation and value will be an important task of image economy; enterprises will have to use more energy to manage these intangible assets. Through the product image to establish in the minds of the consumer loyalty to the product, so that enterprises continue to create a lasting economic value.

As a result of the image, the strength of the product image presents a unique feature - image everywhere, nowhere to be seen, in our table, wardrobe, bedroom bed, window, and even the toilet....... We live, work, entertainment and so on, everywhere is the role of the force, it is no longer short or fleeting, long-term results, strength is almost endless, change the mode of life of individuals and businesses.

In the fierce competition in the modern society, between the enterprises technical difference is almost the same, the output of each enterprise products can be public recognition is key to the success of the enterprise, the relationship between products and consumers are most closely. Therefore, product image is crucial. From a certain meaning, the endorsement of the product image is the corporate image.

\section{References}

1. Wang Zhaoxia, Liang Hao, Tang Lin. Image design - the key to modern product design. Journal of Tianjin University of Science and Technology, 2004:.22-27

2. Liu Yun, who can continue innovation and product image design industry.IT.2003:35-38 decoration.

3. Zhang Linghao, Liu Gang. Visual design of product image. Nanjing: Southeast University press,.2005:46-55

4. Tao Yi. On the brand communication strategy of modern enterprises. Shandong economy, 2005.7

5. Yu Xianglong, Li Juan.VI design. Nanning: Guangxi Fine Arts Publishing House,.2003.6 